\title{
Piggyback technique facilitates off-pump coronary artery bypass graft by using a proximal anastamostic device with arterial conduits
}

\author{
Bobby Yanagawa, MD, PhD, Vicente Orozco-Sevilla, MD, Amit Pawale, MD, and \\ John D. Puskas, MD, MSc, FACS, FACC, New York, NY
}

See related commentary on page 728 .

Minimal aortic touch off-pump coronary artery bypass grafting (OPCAB) with arterial conduits optimizes long-term graft patency while minimizing stroke risk. ${ }^{1}$ Use of clampless proximal anastomotic devices or a completely no-touch aortic technique is associated with lower incidence of stroke. ${ }^{2,3}$ The use of anastomotic devices with small-caliber arterial conduits, however, can result in high-tension anastomoses on the aorta, with a flattened graft hood and poor inflow. We report our outcomes with a novel piggyback technique with the Heartstring III Proximal Seal System (Maquet Deutschland $\mathrm{GmbH}$, Medizinische Geräte und Instrumente Großhandel, Rastatt, Germany). We create an aortocoronary anastomosis with a first conduit (graft A) followed by a second anastomosis with a second graft on the hood of the first (graft B), thus creating an augmentation plasty effect to eliminate any flattening of the arterial conduits that might narrow inflow to the grafts.

\section{CLINICAL SUMMARY}

Between August 2014 and March 2015, a total of 17 patients with coronary artery disease underwent isolated OPCAB with the piggyback technique by a single surgeon (J.D.P.). The mean age was $62.9 \pm 9.1$ years, $6 \%$ were female, $67 \%$ had diabetes, and $6 \%$ had preoperative renal insufficiency. This study was approved by our institutional research ethics board, and individual consent was waived.

After conduit harvest, distal anastomoses were constructed with the assistance of pericardial retraction, cardiac positioners (Starfish Heart Positioner, Medtronic

\footnotetext{
From the Department of Cardiovascular Surgery, Icahn School of Medicine at Mount Sinai and Mount Sinai Beth Israel, New York, NY.

Disclosures: Authors have nothing to disclose with regard to commercial support.

Received for publication April 19, 2015; revisions received May 16, 2015; accepted for publication May 23, 2015; available ahead of print July 7, 2015.

Address for reprints: John D. Puskas, MD, MSc, FACS, FACC, Department of Cardiovascular Surgery, Mount Sinai Beth Israel, 10 Nathan D Perlman Place, New York, NY 10003 (E-mail: john.puskas@mountsinai.org).

J Thorac Cardiovasc Surg 2015;150:725-7

$0022-5223 / \$ 36.00$

Copyright (C) 2015 by The American Association for Thoracic Surgery

http://dx.doi.org/10.1016/j.jtcvs.2015.05.065
}

Inc, Minneapolis, Minn) and stabilizers (Octopus Tissue Stabilizer, Medtronic), retractor tapes, and a humidified carbon dioxide blower. All patients underwent aortic assessment with epiaortic ultrasonography. The Heartstring III was used to create an arterial or saphenous vein graft (SVG) anastomosis to the aorta with 6-0 or 7-0 polypropylene with the sutures left untied (graft A; Figure 1). The hood of the artery or SVG directly over the aortotomy was incised longitudinally, and a second arterial conduit anastomosed with 7-0 or 8-0 polypropylene to the hood of the first anastomosis to complete the piggyback (graft B; Figure 1). The suture of the second anastomosis was tied, deairing of the arterial conduits was accomplished by backbleeding, the Heartstring III device was removed, and the suture of the first anastomosis was then tied. Graft flows were measured with a transit-time flow probe (Medistim ASA, Oslo, Norway). The Student $t$ test was used to determine the significance of the differences in measurements in one arm with and without intermittent graft occlusion in the other graft arm.

We performed an average of $4.1 \pm 1.0$ grafts per patient overall (4 grafts in $47 \%, 3$ grafts in $29 \%$, and 5 or 6 grafts in $12 \%)$. Five patients had total arterial grafting (29\%). Piggyback anastomoses were constructed with radial artery (RA) graft on SVG (53\%), RA graft on RA graft (41\%), and free internal thoracic artery graft on SVG $(6 \%)$. This technique was used equally well for 2 left-sided grafts or a left- and right-sided graft. There were no intraoperative graft failures, nor was there any need for graft revision.

Transit-time flow probes revealed good values for both baseline flow and pulsatility index (PI) in both graft $\mathrm{A}$ (flow, $28.8 \pm 12.1 \mathrm{~mL} / \mathrm{min}$; PI, $2.4 \pm 1.0$ units) and graft B (flow, $25.2 \pm 14.7 \mathrm{~mL} / \mathrm{min}$; PI, $2.3 \pm 0.8$ units). In 10 of the 17 patients, we tested the interdependence of graft flows by temporarily occluding graft A and then graft B while measuring flows and PIs in the other graft. Overall, there was very little percentage change in flow or PI in graft A (flow, $+4.1 \% \pm 10.7 \% ; P=.8$; PI, $+3.4 \% \pm 17.3 \%$; $P=.6)$ with occlusion of graft $\mathrm{B}$, nor was there a great change in graft $\mathrm{B}$ (flow, $+4.7 \% \pm 20.1 \% ; P=.8$; PI, $+3.1 \% \pm 19.6 \% ; P>.999)$ with occlusion in graft $\mathrm{A}$, suggesting that flows in both arms of the piggyback were independent of one another. This likely reflects the effectively unlimited inflow available from the aorta into the shared aortotomy. Although differences must exist 


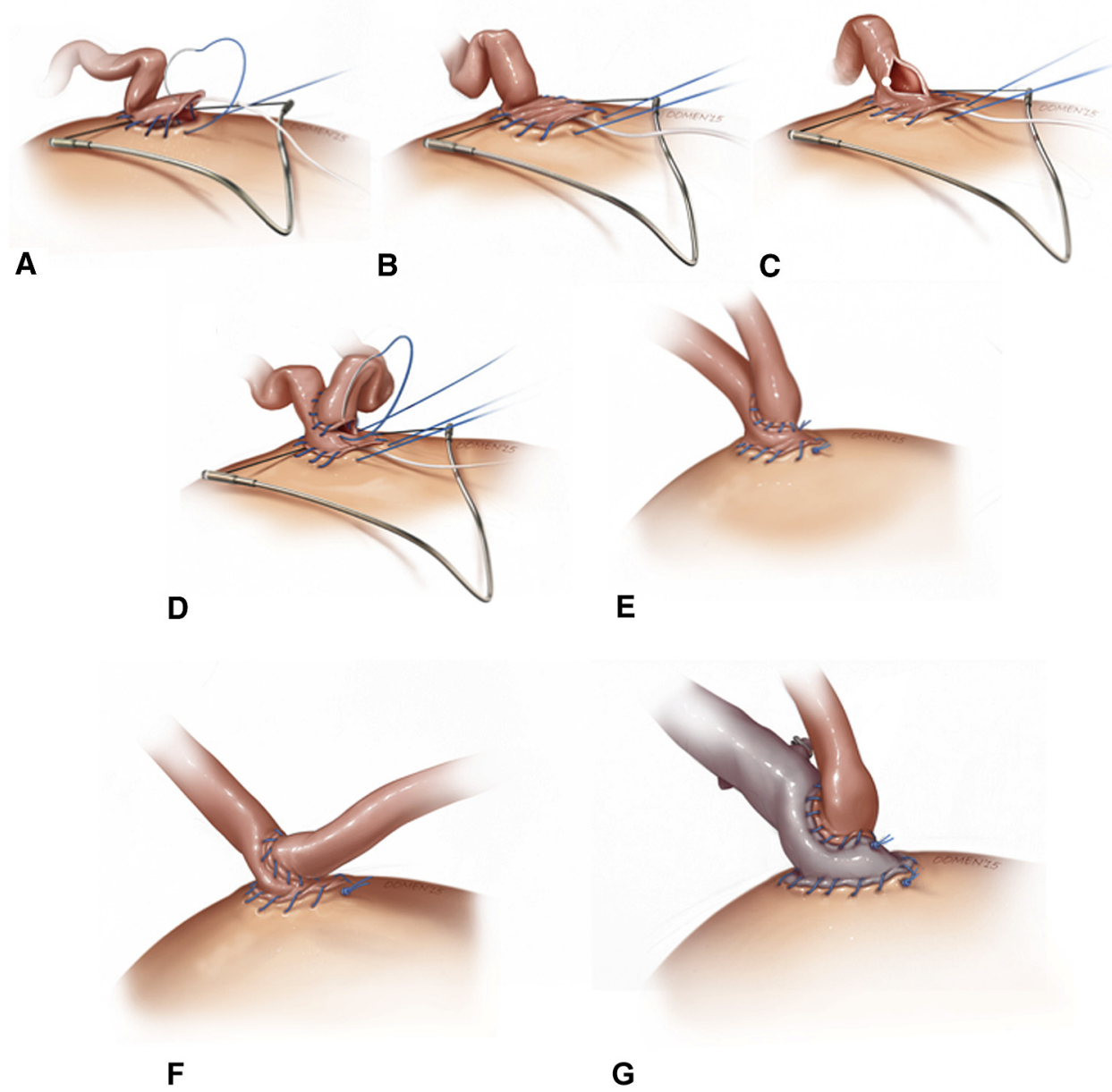

FIGURE 1. A through E: Construction of a piggyback anastomosis. A, An aortocoronary anastomosis using a radial artery. B, Drumlike tension on the flattened hood of the anastomosis. C, Longitudinal incision on the hood of the anastomosis. D, Construction of the piggyback anastomosis. E, Completion of the piggyback, with wide patency of both grafts. F and G: Illustrations of piggyback variations, including opposite direction radial artery graft on radial artery graft (F) and radial artery graft on a saphenous vein graft $(\mathrm{G})$.

between grafts A and B with respect to outflow characteristics (native competitive flow, target vessel diameter, runoff, etc), the independence of flow and PI between grafts was reassuring. In 1 of 10 piggyback anastomoses tested with the flow probe, the flow in graft B increased by $50 \%$ and the PI decreased by $13 \%$ relative to baseline with graft A occluded, suggesting an interdependence of flow (Table 1, highlighted by asterisk).

There were no cases of stroke, myocardial infarction, or operative death.

\section{DISCUSSION}

We describe our piggyback technique for construction of proximal anastomoses by using the Heartstring III device with arterial grafts. The advantages of this technique are (1) avoidance of anastomotic flattening when connecting small-caliber conduits to the aorta with the Heartstring III device, (2) creation of 2 proximal anastomoses with the use of a single Heartstring III device, thereby minimizing aortic manipulation and improving cost-effectiveness, and (3) avoidance of steal between grafts such as may occur with surgically created Y or sequential grafts. Since August 2014, we have been routinely using the piggyback for patients undergoing $\mathrm{OPCAB}$ with multiple arterial or arterial and venous grafts whenever a small-caliber conduit is encountered, and we have noticed no acute or late graft complications.

In 2014, Niclauss and colleagues ${ }^{4}$ reported a similar technique for construction of 2 aortocoronary vein anastomoses to limit aortic manipulation. Our concept expands on this technique to address the size discrepancy between the punch aortotomy (3.8 and $4.3 \mathrm{~mm}$ ) and the small diameter of arterial conduits, particularly with small RA conduits. The average RA inner diameter is $2.2 \pm 0.4 \mathrm{~mm}$, with significantly smaller diameters in women and in patients with lower body mass index. $^{5}$ 
TABLE 1. Operative and postoperative details in 10 patients undergoing off-pump coronary artery bypass grafting with piggyback anastomosis

\begin{tabular}{|c|c|c|c|c|c|}
\hline \multirow[b]{2}{*}{ Case } & \multirow[b]{2}{*}{ Piggyback type } & \multicolumn{2}{|c|}{ With other graft not occluded } & \multicolumn{2}{|c|}{ With other graft occluded } \\
\hline & & Flow & PI & Flow (\% change) & PI (\% change) \\
\hline \multirow[t]{2}{*}{1} & A: RA to OM1 & 19 & 3.2 & $20(+5 \%)$ & $2.3(-28 \%)$ \\
\hline & B: SVG to OM3 & 10 & 2.5 & $12(+20 \%)$ & $2.5(0 \%)$ \\
\hline \multirow[t]{2}{*}{2} & A: RA to OM1 & 40 & 1.8 & $34(-15 \%)$ & $1.8(0 \%)$ \\
\hline & B: SVG to OM3 & 12 & 2.3 & $18(+50 \%)^{*}$ & $1.7(-13 \%)^{*}$ \\
\hline \multirow[t]{2}{*}{3} & A: RA to LAD & 24 & 2.3 & $25(+4 \%)$ & $2.4(+4 \%)$ \\
\hline & B: SVG to Diag & 20 & 4.0 & $23(+15 \%)$ & $3.7(-8 \%)$ \\
\hline \multirow[t]{2}{*}{4} & $\mathrm{~A}: \mathrm{RA}$ to $\mathrm{OM}$ & 11 & 1.8 & $10(-9 \%)$ & $1.8(0 \%)$ \\
\hline & B: SVG to Diag & 11 & 1.9 & $11(0 \%)$ & $1.7(-11 \%)$ \\
\hline \multirow[t]{2}{*}{5} & A: LITA to LAD & 32 & 1.9 & $33(+3 \%)$ & $1.9(0 \%)$ \\
\hline & B: SVG to Diag & 35 & 2.7 & $24(-31 \%)$ & $3.5(+30 \%)$ \\
\hline \multirow[t]{2}{*}{6} & A: RA to $\mathrm{OM}$ & 21 & 5.0 & $23(+10 \%)$ & $6.5(+30 \%)$ \\
\hline & B: SVG to PDA & 18 & 2.9 & $18(0 \%)$ & $2.9(0 \%)$ \\
\hline \multirow[t]{2}{*}{7} & A: RA to $\mathrm{OM}$ & 27 & 2.3 & $22(-19 \%)$ & $3.0(+30 \%)$ \\
\hline & B: RA to Diag & 20 & 1.8 & $18(-10 \%)$ & $1.8(0 \%)$ \\
\hline \multirow[t]{2}{*}{8} & A: RA to PDA & 37 & 2.2 & $39(+5 \%)$ & $2.2(0 \%)$ \\
\hline & B: SVG to OM & 29 & 1.7 & $29(0 \%)$ & $1.5(-12 \%)$ \\
\hline \multirow[t]{2}{*}{9} & A: RA to PDA & 24 & 1.5 & $29(+21 \%)$ & $1.3(-13 \%)$ \\
\hline & B: SVG to Diag & 45 & 1.9 & $48(+7 \%)$ & $1.8(-5 \%)$ \\
\hline \multirow[t]{2}{*}{10} & A: RA to $\mathrm{OM}$ & 53 & 1.8 & $56(+6 \%)$ & $1.7(1.7 \%)$ \\
\hline & B: RA to PDA & 52 & 1.2 & $48(-4 \%)$ & $1.8(+50 \%)$ \\
\hline \multirow[t]{2}{*}{ Mean } & A & $28.8 \pm 12.1$ & $2.4 \pm 1.0$ & $\begin{array}{c}29.1 \pm 12.5(+4.1 \% \pm \\
10.7 \%)\end{array}$ & $2.5 \pm 1.5(+3.4 \% \pm 17.3 \%)$ \\
\hline & B & $25.2 \pm 14.7$ & $2.3 \pm 0.8$ & $24.9 \pm 13.3(4.7 \% \pm 20.1 \%)$ & $2.3 \pm 0.8(3.1 \% \pm 19.6 \%)$ \\
\hline
\end{tabular}

Measurements conducted with probes on corresponding grafts. Flow is measured in $\mathrm{mL} / \mathrm{min}$; pulsatility index (PI) is a dimensionless index; change is given as \%. $A$, Bottom graft; $B$, top graft; RA, radial artery; $O M$, obtuse marginal; SVG, saphenous vein graft; PI, pulsatility index; LAD, left anterior descending coronary artery; Diag, diagonal artery; $L I T A$, left internal thoracic artery; PDA, posterior descending artery. *Piggyback anastomosis in which flow in graft B increased with occlusion of graft A.

Our study has some important limitations. This is an observational experience by a senior surgeon experienced in OPCAB. The long-term performance of these grafts is unknown. Whether this technique can be reproduced with other proximal anastomosis devices has not been reported, but it seems likely.

The piggyback technique is an easy and effective way to facilitate arterial proximal anastomoses with the Heartstring III device. The favorable baseline graft flows and independence of flows in each graft arm suggest that this is a safe and effective technique to avoid flattening of the anastomotic hood of small conduits and to improve the cost-effectiveness of clampless OPCAB.

\section{References}

1. Locker C, Schaff HV, Dearani JA, Joyce LD, Park SJ, Burkhart HM, et al. Multiple arterial grafts improve late survival of patients undergoing coronary artery bypass graft surgery: analysis of 8622 patients with multivessel disease. Circulation. 2012;126:1023-30.

2. Moss E, Puskas JD, Thourani VH, Kilgo P, Chen EP, Leshnower BG, et al. Avoiding aortic clamping during coronary artery bypass grafting reduces postoperative stroke. J Thorac Cardiovasc Surg. 2015;149:175-80.

3. Daniel WT III, Kilgo P, Puskas JD, Thourani VH, Lattouf OM, Guyton RA, et al Trends in aortic clamp use during coronary artery bypass surgery: effect of aortic clamping strategies on neurologic outcomes. J Thorac Cardiovasc Surg. 2014; 147:652-7.

4. Niclauss L, Colombier S, Prêtre R. Single Heartstring aortotomy for multiple off-pump venous bypass grafts. Asian Cardiovasc Thorac Ann. 2015;23:609-11.

5. Velasco A, Ono C, Nugent K, Tarwater P, Kumar A. Ultrasonic evaluation of the radial artery diameter in a local population from Texas. J Invasive Cardiol. 2012; 24:339-41. 